\title{
Laboratory experiments on shear failure of snow
}

\author{
JÜRG SCHWEIZER \\ Swiss Federal Institute for Snow and Avalanche Research, CH-7260 Davos Dorf, Switzerland
}

\begin{abstract}
Using a direct simple-shear apparatus, snow samples (115 $\mathrm{mm}$ in diameter, 16-18 $\mathrm{mm}$ in height) taken from a so-called homogeneous layer (small rounded particles, density: $290 \mathrm{~kg} \mathrm{~m}^{-3}$ ) were tested in a cold laboratory. Experiments were performed for strain rates between $7 \times 10^{-6} \mathrm{~s}^{-1}$ and $5 \times 10^{-3} \mathrm{~s}^{-1}$ at test temperatures of $-5^{\circ} \mathrm{C}$, $-10^{\circ} \mathrm{C}$ and $-15^{\circ} \mathrm{C}$. The effects of strain rate and temperature on failure stress, failure strain, stiffness (initial tangent modulus) and toughness were studied. The transition between the ductile and brittle (sudden fracture) state of failure was found to be at about $1 \times 10^{-3} \mathrm{~s}^{-1}$ for the snow types tested, independent of temperature. Stiffness proved to be the most temperature-dependent property of alpine snow. It strongly increases with decreasing temperature. Failure strain and toughness decrease with decreasing temperature. Failure stress was found to increase slightly with decreasing temperature. The effect is not very distinct but close to statistically significant and might be partly hidden by the scatter in the stress data due to variations inherent in sampling and testing.
\end{abstract}

\section{INTRODUCTION}

To test the behaviour of alpine snow under shear is one of the key experiments to understand slab-avalanche formation. Of particular interest are the failure characteristics in relation to snow type, rate of loading and snow temperature. This study investigates the effect of the latter two above parameters on strength, toughness and stiffness of natural alpine snow samples tested with a direct simple-shear apparatus in a cold laboratory.

Previous testing in shear under laboratory conditions has been done by Fuchs (1949), Ballard and others (1965), McClung (1977), de Montmollin (1982) and Fukuzawa and Narita (1993). McClung (1977) and de Montmollin (1982) used natural samples from an alpine snowpack. McClung (1977) studied the effects of snow type, loading rate and normal load using a direct simple-shear apparatus. In particular, he observed strain-softening; strain rates were rather low between $1.5 \times 10^{-4} \mathrm{~s}^{-1}$ and $2.1 \times 10^{-6} \mathrm{~s}^{-1}$. De Montmollin (1982) performed tests for a wider range of shear rates, including fast tests leading to sudden fracture (brittle failure); he concentrated on the explanation of the stress-strain behaviour by fast metamorphism of the bond system (agehardening) during the tests. Fukuzawa and Narita (1993) showed that snow behaves similarly in shear as in tension, as shown by the pioneering work of Narita (1980). In addition, they also prepared layered samples to study the performance of a so-called weak layer. From these studies (and others in tension or compression), it is known that snow strength is in general highly rate-dependent; strength substantially decreases with increasing strain rate and the failure mode changes from ductile to brittle.

In addition to laboratory testing, substantial work has been done to test snow layers in situ (Roch, 1966; Perla, 1977; Föhn, 1987; Brun and Rey, 1987; Jamieson, 1995). Shear frames of different sizes were mainly used for the field tests involving rapid but less-controlled loading. Recently Föhn and Camponovo (1997) instrumented a shear frame, measured the displacement during tests and calculated the strain rates. Field tests (rapid loading) in general reveal low strength values of the order of $1 \mathrm{kPa}$ or even less. These fast tests seem to correspond well to the fast loading processes during artificial triggering, e.g. by skiers (Schweizer and others, 1995).

The temperature effect on hardness, sintering, compressive and tensile strength of snow has been studied by, e.g. Bucher (1948), Mellor and Smith (1966), Ramseier and Sander (1966), Roch (1966), Gow (1975), Tusima (1975), Salm (1971), Haynes (1978) and Narita (1983). Most work shows that the mechanical properties of dry snow are in general sensitive to temperature and that hardness and strength decrease with increasing temperature. However, the amount of change for the temperature range relevant for slab-avalanche release (the time-scale has also to be considered) seems to be controversial (McClung, 1996).

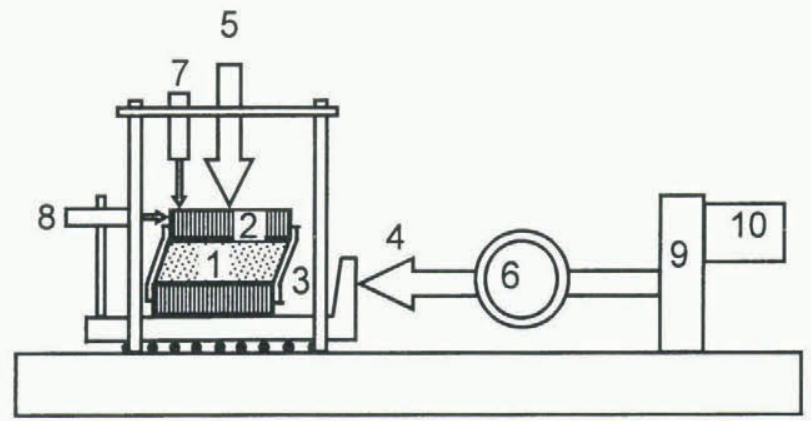

Fig. 1. Schematic of direct simple-shear apparatus: (1) snow sample, (2) caps, (3) membrane, (4) horizontal force, (5) normal force, (6) force gauge, (7) vertical displacement transducer, (8) horizontal displacement transducer, (9) gear box (direct drive), (10) exchangeable motor. 


\section{METHODS}

\section{Test apparatus}

Shear tests were performed in the cold laboratory at Rogers Pass (British Columbia, Canada) with the refurbished Norwegian direct simple-shear apparatus (Bjerrum and Landva, 1966) that was previously used by McClung (1977) (Figs 1 and 2). The snow samples (115 mm in diameter, $16-18 \mathrm{~mm}$ in height) are held between two plastic caps with rough surfaces to prevent slip, surrounded by a wire-reinforced rubber membrane. The membrane prevents any diameter change but allows thickness changes of the sample during the test. This set-up gives plane-strain conditions. However, the stress state is not completely known and the membrane impedes detailed observation of the sample during the test. The top cap is fixed horizontally but can move vertically and takes the normal load which is applied by a weight. The bottom cap is completely fixed to a sledge that is moved horizontally by a motor to induce the shear deformation. The exchangeable motor fixed to the gear box turns at a constant rate. Six different motors were used (Table 1) covering approximately a range of strain rates between $7 \times 10^{-6} \mathrm{~s}^{-1}$ and $5 \times 10^{-3} \mathrm{~s}^{-1}$. Vertical and horizontal displacement of the sample are measured with two linear-displacement transducers. The applied horizontal force is determined by strain gages measuring the deformation of a calibrated proving ring. Data acquisition is computer-controlled. Due to instrumentation and software limitations, the maximum possible scan frequency was only $10 \mathrm{~Hz}$, which proved to be partly insufficient for the fast tests.

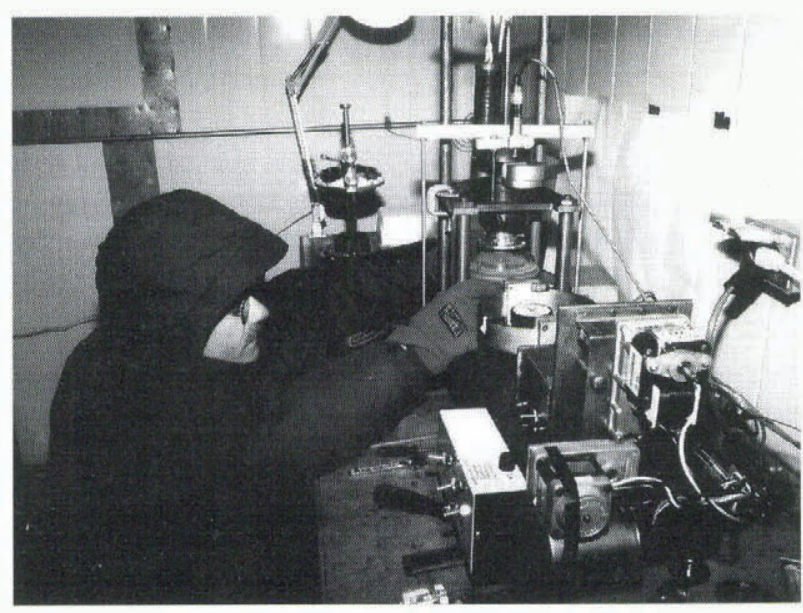

Fig. 2. Direct simple-shear apparatus in the cold laboratory at Rogers Pass: mounting of sample.

Table 1. Displacement or shear rates produced by different motors and corresponding average strain rates

\begin{tabular}{rrll}
\hline Motor & Type of loading & Shear rate & Strain rate \\
& & & \\
\hline 226800 & very slow & $0.0073 \mathrm{~mm} \mathrm{~h}^{-1}$ & $7 \times 10^{-6} \mathrm{~s}^{-1}$ \\
18900 & slow & $0.074 \mathrm{~mm} \mathrm{~h}^{-1}$ & $8 \times 10^{-5} \mathrm{~s}^{-1}$ \\
6000 & intermediate & $0.17 \mathrm{~mm} \mathrm{~min}^{-1}$ & $2 \times 10^{4} \mathrm{~s}^{-1}$ \\
3600 & intermediate & $0.29 \mathrm{~mm} \mathrm{~min}^{-1}$ & $3 \times 10^{-4} \mathrm{~s}^{-1}$ \\
1875 & intermediate & $0.5 \mathrm{~mm} \mathrm{~min}^{-1}$ & $5 \times 10^{-4} \mathrm{~s}^{-1}$ \\
360 & fast & $4.2 \mathrm{~mm} \mathrm{~min}^{-1}$ & $5 \times 10^{-3} \mathrm{~s}^{-1}$ \\
& & & \\
& & &
\end{tabular}




\section{Definitions}

Before analysing the stress-strain curves, it is useful to describe the terms failure, peak and fracture, as well as stiffness and toughness. Failure, peak and fracture refer to three designated points on the stress-strain curve that may or may not be obvious, depending on strain rate (Fig. 4). For the fast tests, the three points coincide, whereas for the very slow tests often only the peak value can be identified. If the stress drops after the peak and the strain increases, the sample shows strainsoftening. If samples are sheared at the slow or very slow rate (Table 1), the stress continues to decrease and finally levels off: so-called residual strength. The stiffness is the initial tangent to the stress-strain curve, also called the initial tangent modulus or shear modulus. It is an effective modulus that might include different contributions of the deformation process. It is not an elastic modulus, except probably for the fast experiments. The initial tangent is determined by a linear regression for the data points at the beginning of the stress-strain curve that show linear behaviour which is, in general, the case below $2 \mathrm{kPa}$. Integrating the stress over strain up to the peak reveals the toughness, which is a measure for the fracture propagation potential, or represents the work needed to reach a peak on the stress-strain curve. The toughness corresponds to the area below the stress-strain curve. Stiffness and toughness are analysed in the light of the slab-release model described by McClung (1996).

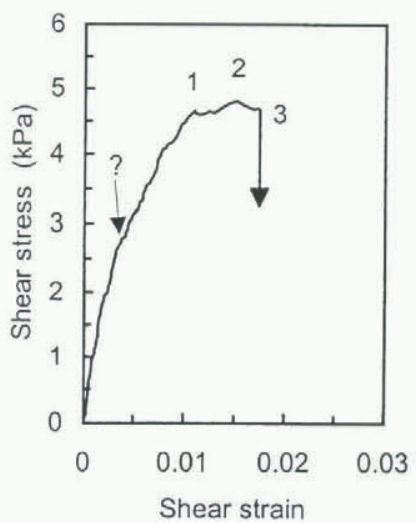

Fig. 4. Stress-strain curve with definitions of failure, peak and fracture (test \#93, strain rate: $2.7 \times 10^{4} \mathrm{~s}^{-1}$, temperature: $-10^{\circ} \mathrm{C}$ ). Question mark indicates an additional kink in the curve of unknown origin, maybe a very first failure.

The results given below are usually for the failure point, since these values of stress and strain show less scatter than the peak values. This results from the fact that, due to ongoing damage after the failure point, deformation behaviour changes and becomes more random.

The shear strain is calculated from horizontal displacement and initial sample height, assuming that the whole sample is homogeneously sheared. The strain rate is the ratio of failure strain to time at failure. It is therefore an average value for the test duration from beginning to failure. The strain rate is generally not constant during a test. It increases in particular after the failure point.

\section{RESULTS}

\section{Effect of strain rate}

Typical stress-strain curves for three different strain rates are shown in Figure 5. Curve (a) shows the response of the stressed snow sample for a strain rate of $7.0 \times 10^{-5} \mathrm{~s}^{-1}$; test duration was $3 \mathrm{~min} 20 \mathrm{~s}$. The curve shows typical strain-softening behaviour with a ductile type of failure characterized by large deformation and high toughness or energy-absorption capability as evidenced by the area under the stressstrain curve. Curve (b) is typical for the tests performed with strain rates of about $10^{-4} \mathrm{~s}^{-1}$ and is believed to be typical for the intermediate range between the purely ductile and brittle behaviour. The curve shows that ductile failures, causing microstructural damage, are going on (as in the slow tests) but the sample finally fails catastrophically after a certain amount of deformation (see also Figs 3 and 4). The test duration is typically about $45 \mathrm{~s}$. Curve (c) shows the result of a fast test (strain rate $6.6 \times 10^{-3} \mathrm{~s}^{-1}$ ). The type of failure is brittle; the sample breaks after very little deformation within fractions of seconds and exhibits minimal toughness. All three samples have been tested at $-15^{\circ} \mathrm{C}$. The faster the shear rate, the larger the initial slope of the stress-strain curve.

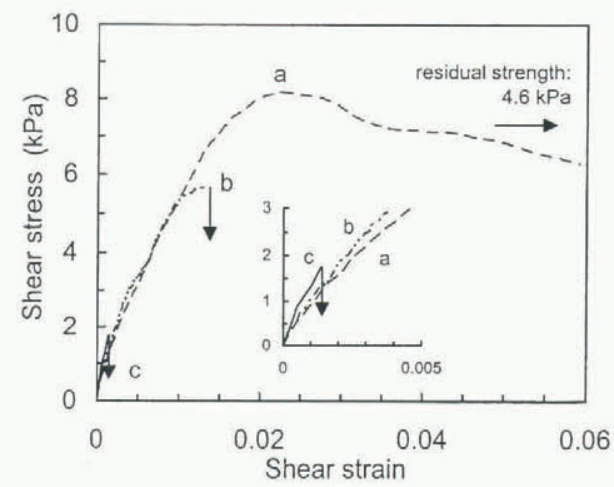

Fig. 5. Typical stress-strain curves for three different strain rates, (a) $7.0 \times 10^{-5} \mathrm{~s}^{-1}$, (b) $2.7 \times 10^{-4} \mathrm{~s}^{-1}$, (c) $6.6 \times 10^{-3}$ $s^{-1}$; insert show details at the beginning, test temperature $-15^{\circ} \mathrm{C}$.

The strain to failure decreases with increasing strain rate in the ductile range and seems to be independent of shearing rate in the brittle range. This feature is independent of temperature. Figure 6 shows the values of failure strain for the samples tested at $-10^{\circ} \mathrm{C}$. The ductile-to-brittle transition is at a strain-rate value of about $1 \times 10^{-3} \mathrm{~s}^{-1}$. Typical values for the failure strain are $3-4 \%$ for the very slow shear rates, $1-2 \%$ in the intermediate ductile range and $0.1-0.3 \%$ in the brittle range.

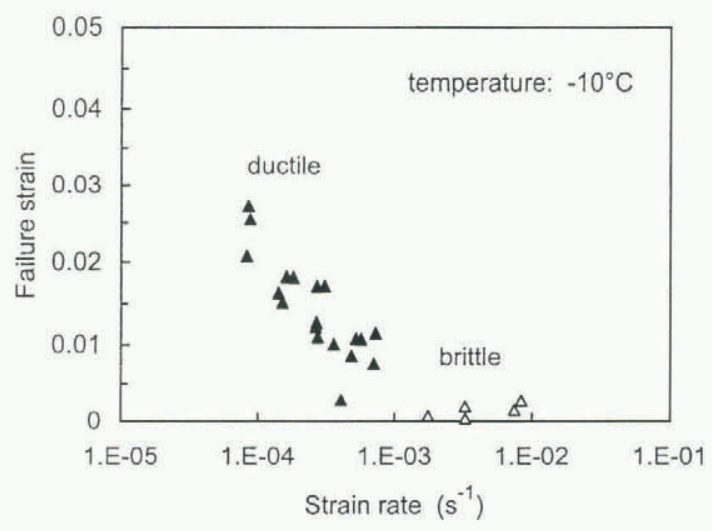

Fig. 6. Failure strain vs strain rate for samples tested at $-10^{\circ} \mathrm{C}$. 
Failure stress (Fig. 7) strongly decreases with increasing strain rate for the whole range of strain rates. Stress values decrease by about a factor 10 from slow to fast loading. Values in the brittle range coincide well with field tests (Roch, 1966).

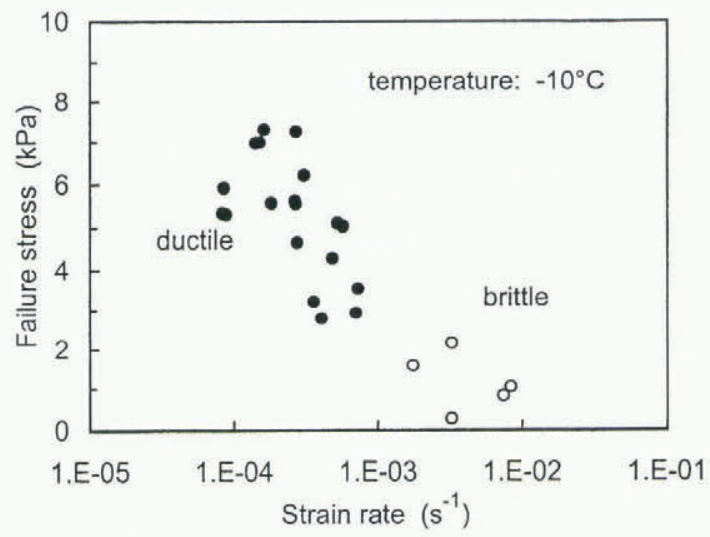

Fig. 7. Failure stress vs strain rate for samples tested at $-10^{\circ} \mathrm{C}$.

Stiffness or initial tangent modulus increases with increasing strain rate (Fig. 8). This is due to the fact that the effective modulus is considered. The overall deformation is the sum of different components of strain, some of which are time-dependent (viscous part). Hence, in the slower tests, deformation is larger resulting in lower stiffness values. Shear-modulus values of the order of $1 \mathrm{MPa}$ are compatible with previous results (Mellor, 1975).

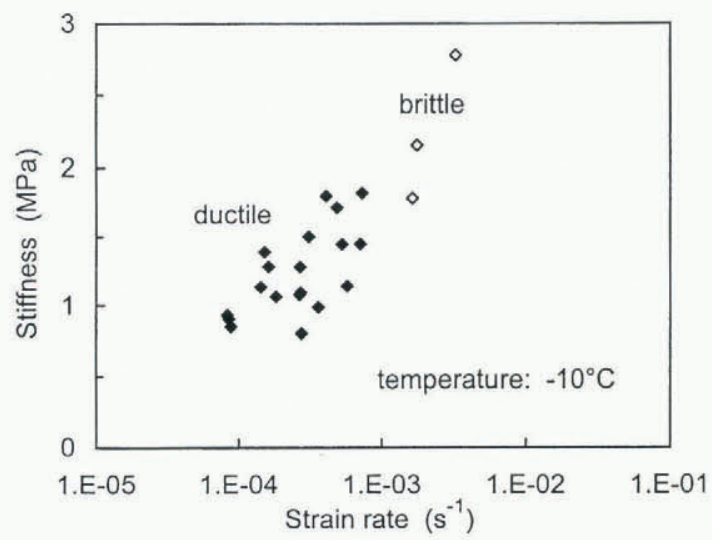

Fig. 8. Stiffness or initial tangent modulus vs strain rate for samples tested at $-10^{\circ} \mathrm{C}$.

The dependence of peak toughness on strain rate shows a similar feature as the failure strain: decreasing with increasing strain rate in the ductile range and independent of strain rate in the brittle range (Fig. 9). Toughness values decrease about a factor 100 from slow $\left(8 \times 10^{-5} \mathrm{~s}^{-1}\right)$ to fast loading $\left(5 \times 10^{-3} \mathrm{~s}^{-1}\right)$.

\section{Effect of temperature}

Figure 10 shows how temperature affects some of the mechanical parameters. Strength and stiffness increase and failure strain decreases with decreasing temperature.

To analyse the effect of temperature statistically the dataset was reduced to the experiments performed with slow and org/10.3189/1998AoG26-1-97-102 Published online by Cambridge University Press intermediate shear rate (Table 1 ). The tests done with the slowest motor (strain rate $7 \times 10^{-6} \mathrm{~s}^{-1}$ ) were not considered, because the snow type of the samples was different for that series of experiments. Also, the fast tests (strain rate $5 \times 10^{-3}$ $\mathrm{s}^{-1}$ ) were not included in the statistical data evaluation, since the results of tests in the brittle range in general show much more scatter than in the ductile range. As cracking dominates, results become more random. In addition, the scan frequency was too low during the fast tests, so that some of the peaks probably have been missed.

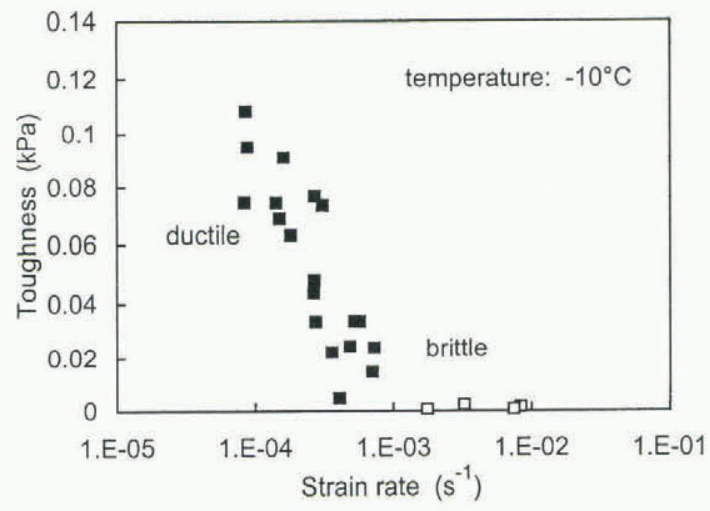

Fig. 9. Failure toughness vs strain rate for samples tested at $-10^{\circ} \mathrm{C}$.

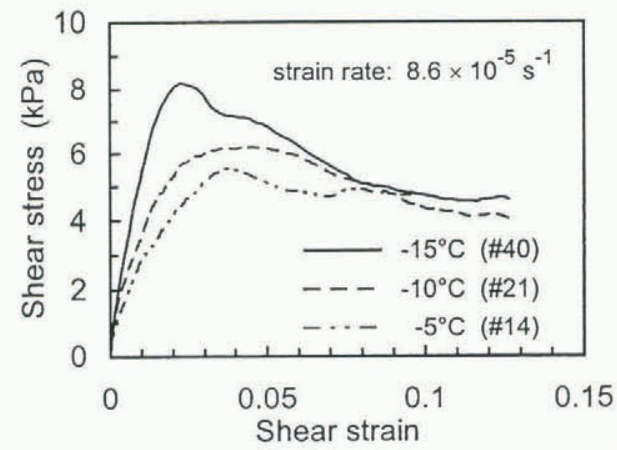

Fig. 10. Typical stress-strain curves for three test temperatures $-5^{\circ} \mathrm{C},-10^{\circ} \mathrm{C}$ and $-15^{\circ} \mathrm{C}$.

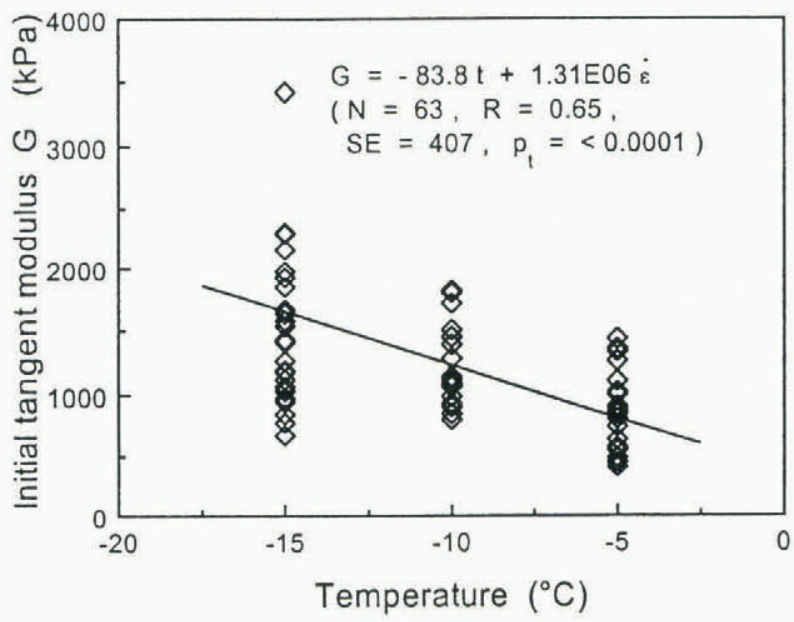

Fig. 11. Stiffness or initial tangent modulus as a function of temperature, together with results of the multiple-regression analysis. 
A multiple regression with Celsius temperature $t$ and strain rate $\dot{\varepsilon}$ as independent variables was performed for failure strain $\varepsilon_{\mathrm{f}}$, failure stress $\tau_{\mathrm{f}}$, stiffness $G$ and toughness $K$. Results of the statistical analysis are shown in Figures 11 to 14 . The multiple regression is given as a line assuming an intermediate strain rate of $3 \times 10^{-4} \mathrm{~s}^{-1}$. In addition, the number of cases $N$, the coefficient of multiple correlation $R$, the standard error of estimate $S E$ and the significance level $p_{\mathrm{t}}$ for the temperature are given. For the other independent variable, the strain rate, the level of significance was always very small ( $p<0.0001$, i.e. highly significant). Based on the multiple-regression analysis, Table 2 summarizes the effect of a temperature decrease from $-5^{\circ} \mathrm{C}$ to $-15^{\circ} \mathrm{C}$ assuming an intermediate strain rate of $3 \times 10^{-4} \mathrm{~s}^{-1}$.

Table 2. Temperature effect on some mechanical properties for a temperature decrease from $-5^{\circ} \mathrm{C}$ to $-15^{\circ} \mathrm{C}$, assuming an intermediate strain rate of $3 \times 10^{-4} s^{-1}$

\begin{tabular}{lc}
\hline Parameter & Relative change \\
& $\%$ \\
\hline Failure strain & $-(48 \pm 33)$ \\
Failure stress & $+(21 \pm 20)$ \\
Stiffness & $+(103 \pm 51)$ \\
Toughness & $-(34 \pm 47)$ \\
\hline
\end{tabular}

The most significant effect of temperature is found for the stiffness or initial tangent modulus (Fig. 11). The modulus strongly increases with decreasing temperature, almost doubling from $-5^{\circ} \mathrm{C}$ to $-15^{\circ} \mathrm{C}$ for the snow samples tested.

The failure stress only slightly increases with decreasing temperature (Fig. 12). As the change in failure stress is of a similar order of magnitude as the scatter in the stress data, there remains some doubt about this result. However, the correlation is close to statistically significant ( $p$ level: 0.018 ) and the order of magnitude is the same as that reported by Salm (1971) for the compressive strength and by Narita (1983) for the tensile strength.

The effect of temperature on failure strain (Fig. 13) is significant but less pronounced than on stiffness and of oppo-

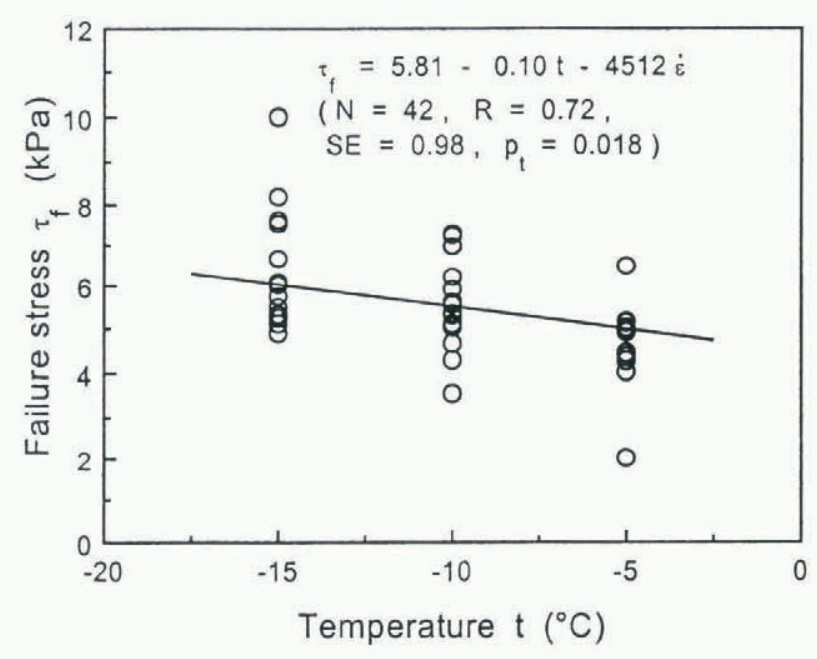

Fig. 12. Failure stress as a function of temperature, together with results of the multiple-regression analysis. site sign compared to stiffness and failure stress. The failure strain decreases for decreasing temperature (i.e. less deformation is needed to start failure for colder snow). This follows directly from the effect on stiffness. The slightly higher stress values and, accordingly larger strain values that are reached before failure starts, do not compensate for the effect on stiffness. The data do not show a significant dependence of the critical strain rate (transition ductile-to-brittle) on temperature.

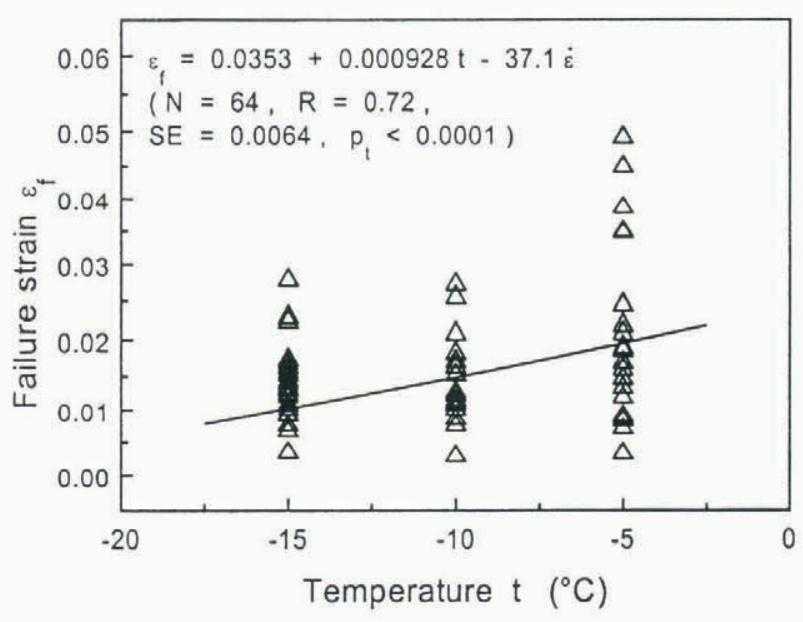

Fig. 13. Failure strain as a function of temperature, together with results of the multiple-regression analysis.

Finally, the toughness also decreases with decreasing temperature (Fig. 14). This result seems to follow from the definition of toughness and the fact that strain decreases but stress only slightly increases with decreasing temperature. It should mean that the colder the snow the lower the energy-absorption capability. Decreasing toughness with decreasing temperature is known from other materials such as steel (Boresi and others, 1993).

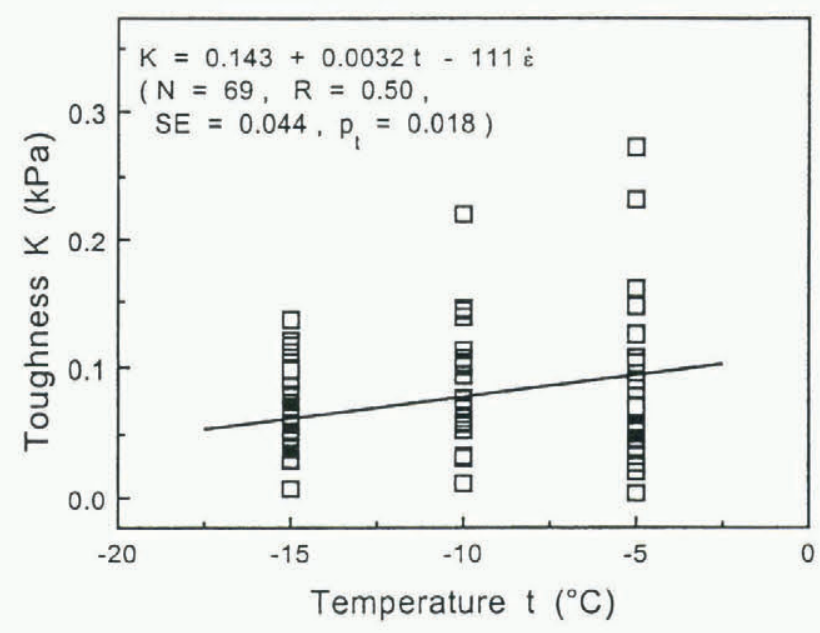

Fig. 14. Toughness as a function of temperature, together with results of the multiple-regression analysis.

\section{CONCLUSIONS}

The results gained with direct simple-shear experiments, varying shear rate and temperature are in general limited to the type of snow, the range of strain rates and temperatures tested. However, general features are probably valid 
in spite of snow type. In addition, the snow type studied, fine-grained, relatively hard and dense snow is important for slab-avalanche release, since it often forms the slab. As has been shown by theoretical studies (McClung, 1987, 1996) and experimental work (Camponovo and Schweizer, 1997), the slab properties are as crucial as the weak-layer properties for assessing snow stability.

Most mechanical properties of snow are shown to be rate-dependent. Tests have been performed for a range of strain rates from $7 \times 10^{-6} \mathrm{~s}^{-1}$ to $5 \times 10^{-3} \mathrm{~s}^{-1}$. Failure stress decreases with increasing strain rate. The same is true for the failure strain but, if the samples suddenly break after very limited deformation (brittle failure), the strain seems to become independent of strain rate. For the snow type tested, the transition between the ductile and the brittle state was at a strain rate of about $1 \times 10^{-3} \mathrm{~s}^{-1}$. The toughness depends similarly on strain rate as failure strain. The stiffness or initial tangent modulus increases with increasing strain rate, probably due to different contributions of the deformation components, some of which are time-dependent.

Stiffness proved to be highly temperature dependent, it roughly doubles from $-5^{\circ} \mathrm{C}$ to $-15^{\circ} \mathrm{C}$. It seems to be the most relevant mechanical property of alpine snow in the study of temperature effect on dry slab-avalanche release (McClung, 1996). Failure strain, the amount of deformation needed before failure starts, and toughness are also significantly temperature-dependent. However, they decrease with decreasing temperature. Failure stress or strength seems to depend only slightly on temperature. It increases about $20 \%$ from $-5^{\circ} \mathrm{C}$ to $-15^{\circ} \mathrm{C}$. The temperature dependence might partly be hidden by the scatter in stress data due to variations inherent in sampling and testing.

\section{ACKNOWLEDGEMENTS}

This study was performed when the author was on leave at the Department of Civil Engineering, University of Calgary, Canada. The advice from D. McClung (University of British Columbia) and T. Berre (Norwegian Geotechnical Institute) is gratefully acknowledged. C. Johnston (University of Calgary) provided technical support and reviewed a previous version of the manuscript. Thanks for logistical support at Rogers Pass are due to R. Beardmore (Mount Revelstoke and Glacier National Parks). Finally, it is a pleasure to thank B. Jamieson (University of Calgary) for many stimulating discussions. During his visit to Canada, the author was supported in part by the Natural Sciences and Engineering Research Council of Canada through a Canada International Fellowship.

\section{REFERENCES}

Ballard, G. E. H., E. D. Feldt and S. R. Toth. 1965. Direct shear study on snow: procedures and data. CRREL Spec. Rep. 92.

Bjerrum, L. and A. Landva. 1966. Direct simple-shear tests on Norwegian quick clay. Oslo, Norges Geotekniske Institutt. (NGI Publication 70.)

Boresi, A. P., R. J. Schmidt and O. M. Sidebottom. 1993. Advanced mechanics of materials. Fifth edition. New York, John Wiley and Sons.

Brun, E. and L. Rey. 1987. Field study on snow mechanical properties with special regard to liquid water content. International Association of Hydrological Sciences Publication 162 (Symposium at Davos 1986 - Avalanche For- mation, Movement and Effects), 183-192.

Bucher, E. 1948. Beitrag zu den theoretischen Grundlagen der Lawinenverbaus. Beitr. Geol. Schweiz, Geotech. - Hydrol. 6.

Camponovo, C. and J. Schweizer. 1997. Measurements on skier triggering. In ISSW'96. International Snow Science Workshop, 6-10 October 1996, Banff, Alberta. Proceedings. Revelstoke, B.C., Canadian Avalanche Association, 100-103.

De Montmollin, V. 1982. Shear tests on snow explained by fast metamorphism. f. Glaciol., 28(98), 187-198.

Föhn, P. M. B. 1987. The stability index and various triggering mechanisms. International Association of Hydrological Sciences Publication 162 (Symposium at Davos 1986 - Avalanche Formation, Movement and Effects), 195-214.

Föhn, P. M. B. 1989. Snowcover stability tests and the areal variability of snow strength. In A Merging of Theory and Practice: Proceedings of the International Snow Science Workshop, 12-15 October 1988, Whistler, B.C. Vancouver, B.C., Canadian Avalanche Association, 262-273.

Föhn, P. M. B. 1993. Characteristics of weak snow layers or interfaces. In Armstrong, R., ed. ISSW'92. International Snow Science Workshop, 4-8 October 1992, Breckenridge, Colorado. Proceedings. Denver, CO, Avalanche Information Center, 160-170.

Föhn, P. and C. Camponovo. 1997. Improvements by measuring shear strength of weak layers. In ISSW'96. International Snow Science Workshop, 6-10 October 1996, Banff, Alberta. Proceedings. Revelstoke, B.C., Canadian Avalanche Association, 158-162.

Fuchs, A. 1949. Die Scherfestigkeit von Schnee und Eis in Abhängigkeit von der Temperatur. Veröff. Mus. Ferdinandeum Innsbruck 26-29, 1946 - 49, 101-105.

Fukuzawa, T. and H. Narita. 1993. An experimental study on mechanical behavior of a depth hoar under shear stress. In Armstrong, R., ed. ISSW'92. International Snow Science Workshop, 4-8 October 1992, Breckenridge, Colorado. Proceedings. Denver, CO, Avalanche Information Center, 171-175.

Gow, A. J. 1975. Time-temperature dependence of sintering in perennial isothermal snow packs. International Association of Hydrological Sciences Publication 114 (Symposium at Grindelwald 1974 - Snow Mechanics), 25-41.

Haynes, F. D. 1978. Effect of temperature on the strength of snow-ice. CRREL Rep. 78-27.

Jamieson, J. B. 1995. Avalanche prediction for persistent snow slabs. (Ph.D. thesis, University of Calgary.)

McClung, D. M. 1977. Direct simple shear tests on snow and their relation to slab avalanche formation. J. Glaciol., 19(81), 101-109.

McClung, D. M. 1987. Mechanics of snow slab failure from a geotechnical perspective. International Association of Hydrological Sciences Publication 162 (Symposium at Davos 1986 - Avalanche Formation, Movement and Effects), 475-508.

McClung, D. M. 1996. Effects of temperature on fracture in dry slab avalanche release. 7. Geophys. Res., 101 (B10), 21,907-21,920.

Mellor, M. 1975. A review of basic snow mechanics. International Association of Hydrological Sciences Publication 114 (Symposium at Grindelwald 1974-Snow Mechanics), 251-291.

Mellor, M. and J. H. Smith. 1966. Strength studies of snow. CRREL Res. Rep. 168.

Narita, H. 1980. Mechanical behaviour and structure of snow under uniaxial tensile stress. .7. Glaciol., 26(94), 275-282.

Narita, H. 1983. An experimental study on tensile fracture of snow. Contrib. Inst. Low Temp. Sci., Ser. A 32, 1-37.

Perla, R. 1977. Slab avalanche measurements. Can. Geotech. 7., 14(2), 206-213.

Ramseier, R. O. and G.W. Sander. 1966. Sintering of snow as a function of temperature. International Association of Scientific Hydrology Publication 69 (Symposium at Davos 1965 - Scientific Aspects of Snow and Ice Avalanches, $119-127$.

Roch, A. 1966. Les variations de la résistance de la neige. International Association of Scientific Hydrology Publication 69 (Symposium at Davos $1965-$ Scientific Aspects of Snow and Ice Avalanches), 86-99.

Salm, B. 1971. On the rheological behavior of snow under high stresses. Contrib. Inst. Low Temp. Sci., Ser. A 23, 1-43.

Schweizer, J., C. Camponovo, C. Fierz and P. M. B. Föhn. 1995. Skier triggered slab avalanche release - some practical implications. In Sivardière, F., ed. Les apports de la recherche scientifique à la sécurité neige, glace et avalanche. Actes de Colloque, Chamonix 30 mai-3 juin 1995. Grenoble, Association Nationale pour l'Étude de la Neige et des Avalanches (ANENA), 309-315.

Tusima, K. 1975. The temperature dependence of hardness of snow. International Association of Hydrological Sciences Publication 114 (Symposium at Grindelwald 1974 - Snow Mechanics), 103-109. 